\title{
EDITORIAL
}

\section{Mixed Methods: Capturing Complexity in Family Medicine Research}

\author{
Simon J. Craddock Lee, PbD, MPH, Associate Editor \\ Ann Fam Med 2021;19:98-99. https://doi.org/10.1370/afm.2682.
}

I

n 2004, Borkan advocated for qualitative and mixed methods as important research strategies to address key challenges facing family medicine as a scientific discipline. ${ }^{1}$ These study designs help researchers capture the complexity inherent to the practice of family medicine with clarity and rigor. More recently, experts advocated for the use of qualitative and mixed methods to untangle the causal pathways in health disparities research. ${ }^{2}$ Qualitative data can corroborate and expand on quantitative research results, but only if data collection is carefully designed to capture the complexity. One design strategy is to develop a vision of how quantitative and qualitative results would ideally be jointly displayed and then work backward to design data collection strategies to get there. ${ }^{3}$

In this issue, a mixed methods analysis led by Solberg et $\mathrm{al}^{4}$ sought to unpack in a sequential design how leaders at high- and low-performing clinics in Minnesota thought they were managing diabetes. Their data displays stratified high and low clinics by quantitative performance metrics (Solberg, Table 1) and by qualitative code and comment frequency (Solberg, Table 2).

They adjusted for socioeconomic status before stratifying clinic performance to select their interview targets from among clinical leaders. That adjusted sample frame meant authors could be confident when the qualitative analysis detected no relationship between clinic performance and patient mix. Initially, all the care strategies reported in interviews seemed to hang together, however, although the number of comment/ clinic reflecting proactive approaches did not differ, as quotes show, the content was dramatically different by clinic performance. These differences led authors

Conflicts of interest: author reports none.

\section{CORRESPONDING AUTHOR}

Simon J. Craddock Lee

University of Texas Southwestern Medical Center

5323 Harry Hines Blvd, MSC 9066

Dallas, TX 75390-9066

simoncraddock.lee@utsouthwestern.edu to distinguish between a traditional visit-based model "with individual patient responsibility for attendance and adherence" and a proactive model where the clinic teams used panel reports to drive systematic outreach (mail, e-mail, telephone) while also taking "advantage of visits for any reason to reinforce those suggestions..." The paper's analytic meta-framework shows no single step from one-on-one doctor-patient relationship but more of an evolution that leveraged "reminder systems, checklists, data audit and feedback, and patient education" to drive proactive clinic behaviors. John Frey has warned that continuity cannot simply be systems managing the disease without the patient. ${ }^{5}$ These multisite data help us see a way forward for care monitoring systems to empower the broader clinic team and reinvigorate patient engagement.

Wolk et $\mathrm{al}^{6}$ describes a staged implementation of the Collaborative Care Model (CoCM) to integrate mental health treatments in primary care, following the RE-AIM framework (ie, reach, effectiveness, adoption, implementation, and maintenance). The first year saw over 6,000 patients referred, nearly $7 \%$ of empaneled patients! Penn Integrated Care featured a centralized mental health resource center for intake, triage, and referral if indicated. Authors noted, "effectiveness often declines when programs move from efficacy trials to real world implementation" but in this study, length and frequency of treatment suggest high fidelity for CoCM services; rates of enrollment, symptom reduction, and remission are consistent with results from randomized controlled trials. From a service perspective, the multilevel triage met patient demand while allowing mental health clinicians to focus on treatment delivery.

Mixed-method results can help bridge the gap for decision makers seeking to disseminate programs. ${ }^{7}$ Fortin et $\mathrm{al}^{8}$ report on a pragmatic randomized controlled trial of an integrated care management pathway to change how multimorbidity care is delivered. When the regional health authority adapted the intervention for regional dissemination, it altered the intervention design increasing the pragmatic dimension of the trial. At 4 months, the intervention did not improve the 
primary outcome of self-management, but did improve secondary outcomes including physical activity and healthy eating. The concurrent triangulation mixedmethod design, with quantitative and qualitative components, produced divergent results demonstrating that implementation may influence intervention effects on patient outcomes. Mixed methods also mean researchers have more results from various sources to help elucidate unexpected findings.

Fortunately, primary care scholars are generating new family medicine practice-based evidence across the implementation and dissemination research continuum. ${ }^{9}$ Research on practice change draws explicitly on theory and measurement. Implementation science uses learning health systems and other real-world "collaboratories"10 to "bake-in" external validity from the beginning. ${ }^{11}$ As the theme of "living laboratories" at the 2020 PBRN meeting suggested, ${ }^{12}$ the interface of implementation science and health care delivery research has continued to draw significant attention in primary care. We hope this attention persists and encourage it among our readership.

Annals of Family Medicine will champion research methods that reflect complexity of primary care practice, particularly the persistent challenge of adopting and disseminating evidence-based guidelines and interventions. Our editorial team invites our readers and authors to advance the field by reading and submitting such work.

To read or post commentaries in response to this article, go to https://www.AnnFamMed.org/content/19/2/98/tab-e-letters.

Key words: mixed methods; primary care research; complexity Submitted February 12, 2021; accepted February 15, 2021.

\section{References}

1. Borkan JM. Mixed methods studies: a foundation for primary care research. Ann Fam Med. 2004;2(1):4-6.

2. Jeffries N, Zaslavsky AM, Diez Roux AV, et al. Methodological approaches to understanding causes of health disparities. Am J Public Health. 2019;109(S1):S28-S33.

3. Guetterman TC, Fetters MD, Creswell JW. Integrating quantitative and qualitative results in health science mixed methods research through joint displays. Ann Fam Med. 2015;13(6):554-561.

4. Solberg LI, Peterson KA, Fu H, Eder M, Jacobsen R, Carlin CS. Strategies and factors associated with top performance in primary care for diabetes: insights from a mixed methods study. Ann Fam Med. 2021;19(2):110-116.

5. Frey JJ III. Colluding with the decline of continuity. Ann Fam Med. 2018;16(6):488-489.

6. Wolk CB, Last BS, Livesey $C$, et al. Addressing common challenges in the implementation of collaborative care for mental health: the Penn Integrated Care program. Ann Fam Med. 2021;19(2):148-156.

7. Miller WL, Crabtree BF, Harrison MI, Fennell ML. Integrating mixed methods in health services and delivery system research. Health Serv Res. 2013;48(6 Pt 2)(6pt2):2125-2133.

8. Fortin M, Stewart M, Ngangue $P$, et al. Scaling up patient-centered interdisciplinary care for multimorbidity: a pragmatic mixed-methods randomized controlled trial. Ann Fam Med. 2021;19(2):128-134.

9. Miller WL, Rubinstein EB, Howard J, Crabtree BF. Shifting implementation science theory to empower primary care practices. Ann Fam Med. 2019;17(3):250-256.

10. Weinfurt KP, Hernandez AF, Coronado GD, et al. Pragmatic clinical trials embedded in healthcare systems: generalizable lessons from the NIH Collaboratory. BMC Med Res Methodol. 2017;17(1):144.

11. Green LW. Making research relevant: if it is an evidence-based practice, where's the practice-based evidence? Fam Pract. 2008; 25(Suppl 1):i20-i24.

12. Nease D Jr, Greiver M. 2020 PBRN conference highlights: living laboratories for innovation and dissemination/implementation in our communities. Ann Fam Med. 2020;18(6):569-570.

\title{
Thank You, Reviewers and E-Letter Contributors!
}

\author{
Ann Fam Med 2021;19:99. https://doi.org/10.1370/afm.2681.
}

$\mathrm{T}$

This year we are even more grateful than ever for our reviewers (full list of reviewers for 2020).

The year 2020 tested the limits of all of us, and none more so than the frontline medical workers who provided care for coronavirus disease 2019 (COVID19) patients, risking their own lives and health. Many people across primary care whom we invited to review manuscripts - often about COVID-19—wrote back that they were unable to take on any nonessential task. We thank them for their bravery, their skill, their energy.

Those who did review for us stepped up where others could not and provided us with the intellectual depth, interpretive understanding, and useful criticism without which a peer-reviewed publication cannot exist. And they did so in large numbers: this year we received 443 reviews, a record-breaking year for Annals of Family Medicine.

In addition, our Editorial Advisory Board and Associate Editors volunteered and reviewed 175 manuscripts submitted to our COVID-19 Collection, a spur-of-the-moment invention that enabled us to post up-to-the-moment preprints in rapid-fire time. For their willingness to give their time and expertise to this enterprise, we give our heartfelt gratitude.

And, as ever, the Annals is enriched by those who contributed e-letters. In 2020, we posted 43 e-letters reflecting on a wide range of published articles. Our sincere thanks to those who participated in this stimulating dialogue. You can read our most current e-letters on our homepage at www.AnnFamMed.org. 